\title{
APPARATUS AND EXPERIMENTS FOR THE INTRODUCTORY COURSE
}

\author{
BY HOWARD C. WARREN AND PRENTICE REEVES \\ Princeton University
}

\section{A Combined Tilting Board and Rotation Table}

Apparatus.-This is a modification of the two pieces of apparatus described in Sanford's 'Course.' The board used in the combination is $6 \mathrm{ft}$. 4 in. long, $2 \mathrm{ft}$. wide, and $1 \frac{1}{2}$ in. thick. At each end a piece of $3 \frac{1}{2} \times \mathrm{I}_{2} \frac{1}{2}$ inch pine is nailed on the upper side to serve as a brace as well as to prevent the subject from slipping during the tilting experiment. Near each end notches are cut in the side to serve as grooves for the straps which hold the subject in position. Beneath the center of the board is fastened the swivel screw from an office chair for the horizontal rotation, and across the middle of the board is a steel axle about which the board rotates vertically in the tilting experiment. This axis projects about 3 inches beyond each edge of the board.

The figure (Fig. I) shows the apparatus used as a tilting board with a subject strapped on as in an experiment. One support for the board, in shape of an $A$, is permanently fixed to the wall and is made of yellow pine. The other support, of $4 \times 3$ in. white pine, is a post which extends from floor to ceiling and is removed when not in use. A hole in the ceiling slightly larger than this upright allows it to just slip through and the fit is then made snug by V-shaped wedges. On the bottom of the upright is a small iron projection which fits into a hole in the floor. The bearings for the axis of vertical rotation are $\mathrm{Y}$-shaped and are made of steel. These bearings are securely fastened to the supports just high enough to allow about six inches clearance from the floor when the board stands vertical. Thus the subject may be rotated through all angular positions from the natural upright position to a position in which his head is straight down. An angular. 454 
scale with a plumb bob is attached to the board so that all angular positions are read directly.

Procedure.--In the introductory course the tilting experiment is conducted as follows: The subject, with eyes closed, is strapped to the board; one experimenter holds each end of the board, and usually a third reads and records the judgments. (a) The experimenters slowly rock the board up

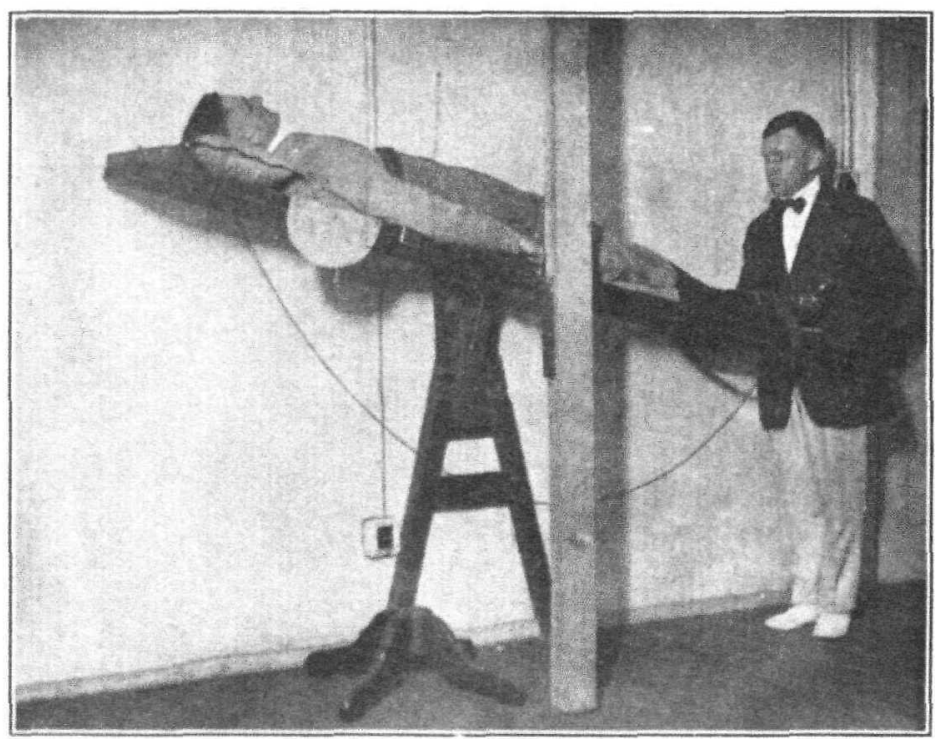

FIG. I.

and down a few times and the subject then directs the movement until he judges his body parallel to the floor. The scale reading is recorded in a column headed 'Level.' (b) The board is then slowly rotated so that the subject's head rises; the subject directs the movement until he judges himself to be 'half-way up' and this is recorded under $+45^{\circ}$. (c) The rotation is continued until the subject judges himself perpendicular to the floor. Recorded under $+90^{\circ}$. $(d, e)$ The direction of rotation is now reversed and the subject again indicates the 'half-way' and 'level.' ( $f, g, h, i)$ Continuing the rotation, the subject's head is moved down and he indicates the $-45^{\circ}$ and $-90^{\circ}$ points. Reverse the 
movement and determine $-45^{\circ}$ and 'Level.' (These last four readings should be taken as rapidly as possible.)

The subject works out the deviation for each position, and in this way learns to what extent one is ordinarily dependent on vision in determining the position of the body.

To use the board as a rotation table for horizontal rotation it is easily lifted from the supports and screwed into the base of an office chair by means of the swivel screw. It is then free to rotate horizontally and is operated by a stout cord fastened to each end of the board.

In the introductory course the rotation table is used as a class demonstration. The subject, eyes closed, lies on the table with his head on a partly inflated air pillow. When the subject detects motion he indicates the direction by raising the hand on the side toward which his head is moving and keeps his hand raised as long as the motion is felt. The experimenter at first rotates the table very slowly and the remainder of the class observe that no motion is detected by the subject. (b) The rate of motion is increased by the experimenter and then rather suddenly the table is stopped. The subject lowers one hand and raises the other, indicating an apparent rotation in the opposite direction.

(c) The experimenter again rotates the table at a uniform rate for several complete revolutions and watches the subject's hands. Then slowly the rate of motion is decreased. Fatigue causes an apparent cessation of movement as shown by the subject dropping his hand, and often a reversal will be indicated on decreasing the rate of motion.

(d) Next the subject turns his head so as to rest on one ear and the experimenter rotates the board at a medium velocity. As soon as the subject indicates that the motion has apparently stopped he is directed to turn his head quickly to the other side and note the effect. The direction of stimulation in the fatigued organs is reversed and the sense of motion is taken up again in the same objective direction.

Each student takes notes on his observation of other subjects, and records his own sensations when acting as subject. 


\section{A Size-Weight Illusion Experiment}

Numerous size-weight experiments have been offered with varying degrees of success, but they often involve special apparatus. The apparatus used in this experiment (Fig. 2) can be duplicated in any laboratory without extra expense. If any object here mentioned is not available it can easily be replaced by some similar article.

Seventeen articles are included in the experiment; this

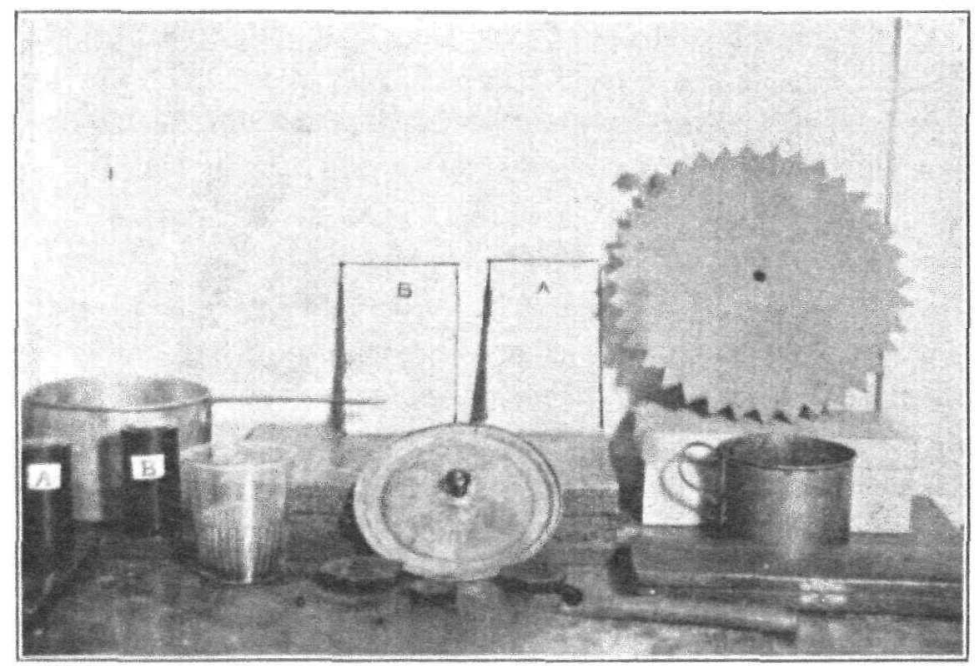

FIG. 2 .

number may be increased or diminished, as the crucial point is the various classes of objects used rather than their number. The articles may be classed as follows: I. Compact solid, II. flat, III. long slender, IV. cylindrical, V. hollow closed, and VI. hollow open.

Articles tised

1. Ordinary sauce pan with handle.

2. Jastrow ylinder $A$, weighted with shot and cotton 350

3. Milton Bradley pseudoptic box empty. . . . . . . . . . . . . 255

4. Esthesiometer (Verdin) box.......................250

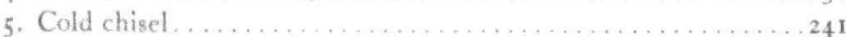

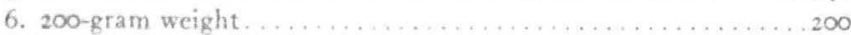

7. Glass tumbler............................... 200

8. Ruler, anthropometric ....................... 440
Class VI

IV

V

V

I

I

VI

III 
9. Buzz-saw disk of heavy cardboard $\ldots \ldots \ldots \ldots \ldots \ldots \ldots \ldots \ldots$

10. Tin cup..............................

I I. Ioo-gram weight. .......................... 100

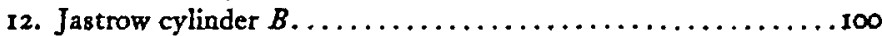

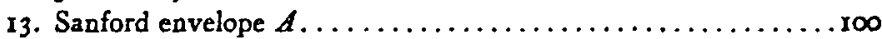

14. Pasteboard box, Library Bureau................. 88

15. Saucepan lid.............................. 85

16. Sanford envelope $B \ldots \ldots \ldots \ldots \ldots \ldots \ldots \ldots \ldots \ldots, 82$

17. 50 -gram weight......................... 50

Procedure.-The articles are distributed at random on a table and the subject is told to arrange them in order of weight by lifting them in pairs. The two objects to be compared are lifted successively in the same hand, with the eyes open. The experimenter may start the subject by placing in proper order the three scale weights (the only objects marked) as an illustration of the problem. These weights will then serve as starting points for further comparisons. After the subject has placed all the articles in order he is allowed to go over the entire set and revise his judgment. When the final order is reached the experimenter gives the subject the correct weight of each article. The subject is instructed to compare his arrangement of the articles with the correct order and to note the relative displacement of each class of articles to right or left, as well as the displacement of the individual articles. No subject acts as experimenter or sees the work of another subject until after he himself has served as subject.

The experiment has been given in the Princeton Laboratory for a number of years and the records of II4 subjects have been kept. In no case has the illusion been absent, while in practically all cases it has been quite pronounced, even though the subject knew the nature of the experiment beforehand. 39 out of the 45 subjects using the articles as here described placed cylinder $A$ at the heavy end, while the saucepan was displaced from one to eight places toward the light end and was correctly placed by only three subjects. The pasteboard box, No. ${ }_{4}$ in weight order, was placed at the light end by 37 out of 45 subjects and the 50 -gram weight was correctly placed by only two subjects. A typical atrangement of the articles is: $2,5,6,1,11_{2} 9,13,4,17,6,16,10$, 
$15,8,12,3,14$. The individual result in which the illusion was most markedly absent is: $1,2,4,3,5,8,9,7,6,10,1_{5}$, II, 13, 14, 12, 16, 17 .

At the same laboratory period the subjects are also given Whipple's Suggestion Blocks. ${ }^{1}$

I Whipple's 'Manual of Mental and Physical Tests,' Test 40. The reference also contains a bibliography of references on size-weight illusions. 